W. SzCZOTKA (Wroclaw)

\title{
FACTORIZATION OF THE DISTRIBUTION FUNCTION OF WAITING TIME
}

1. Introduction. The main result of this paper is to show that in a sufficiently wide class of queueing systems the limiting distribution of the waiting time is the same as the distribution of the supremum of the process

(1)

$$
\xi(t)=\sum_{j=1}^{[t]} \xi_{j}, \quad t \geqslant 0,
$$

Where $\left\{\xi_{k}, k \geqslant 1\right\}$ is a stationary sequence of random variables (r. $v$. 's), and $[\cdot]$ denotes the entier function. For convenience we put zero for the by having an empty set of indices. To simplify our notation, we denote their $\left\{a_{k}\right\}$ any sequence for which $k \geqslant 1$. If we need other sequences, then $\left\{a_{k},-\infty\right.$ of indices is indicated within the sequence brackets, e.g. be any limit $k<\infty\}$. By our assumptions we show that the process $\xi$ can gence limit of a subsequence of the sequence $\left\{\mathbb{S}_{k}\right\}$ in the sense of conver$(D, d)$ in distribution in $(D, d)$ (seo [3]), where a random element $S_{k}$ of ,d) is defined by

$$
S_{k}(t)=\sum_{j=[k-t+]+1}^{k} X_{j}, \quad t \geqslant 0,
$$

for some sequence $\left\{X_{k}\right\}$ of r. $\nabla$.'s. Here the symbol $\left[k-t_{0}+\right]$ denotes the paper we limit of $[k-t]$ at the point $t_{0}<k$ and zero for $t_{0} \geqslant k$. In the traffic. Let $\left\{X_{k}\right\}$ be any sequence of r. $\nabla . ' s$ and let

(2)

$$
w_{k}=S_{k}-\inf _{0 \leqslant j \leqslant k} S_{j}, \quad k \geqslant 0,
$$

Where $S_{0}=0, S_{k}=S_{k-1}+X_{k}, k \geqslant 1$, and $w_{k}$ is interpreted as the waiting ${ }^{2}-z_{\text {astosow. Matem. } 16.3}$ 
It has been shown in [4] that if $\left\{X_{k},-\infty<k<\infty\right\}$ is a stationary and ergodic sequence of r. $\nabla$.'s and $\mathrm{E} X_{1}<0$, then

$$
w_{k} \stackrel{D}{\rightarrow} w, \quad \mathbf{P}\{w<\infty\}=1,
$$

and

$$
w \stackrel{D}{=} \sup _{0 \leqslant j<\infty} S_{j}
$$

where $S_{0}=0, S_{k}=S_{k-1}+X_{-k}, k \geqslant 1$. Let us note that (3) can be written as

$$
w \stackrel{D}{=} \sup _{0 \leqslant t<\infty} S^{-}(t)
$$

where $S^{-}$is a random element of $(D, d)$ defined by

$$
S^{-}(t)=\sum_{j=1}^{[t]} X_{-j}, \quad t \geqslant 0 .
$$

In [2] and [5] one considers the class of queueing systems described by sequences $\left\{X_{k}\right\}$ defined in the following way:

Let $\zeta_{i}=\left\{X_{i, k}, k \geqslant 1\right\}, i \geqslant 1$, where $X_{i, k}$ are r. $\nabla$.'s. Let the processes $\zeta_{1}, \zeta_{2}, \ldots$ be independent and identically distributed. Write the sequence of r. $\nabla . ' s$

$$
\begin{gathered}
r_{i}=\min \left\{j: X_{i, 1}+X_{i, 2}+\ldots+X_{i, j} \leqslant 0\right\}, \quad i \geqslant 1, \\
R_{0}=0, \quad R_{k}=R_{k-1}+r_{k}, \quad k \geqslant 1, \\
\eta_{k}=\max \left\{j: R_{j}<k\right\}, \quad \gamma_{k}=k-R_{\eta_{k}}, \quad k \geqslant 1, \\
X_{k}=X_{\eta_{k}+1, \gamma_{k}}, \quad k \geqslant 1 .
\end{gathered}
$$

It is proved in [3] that if $E r_{1}<\infty$ and the distribution of $r_{1}$ is nonperiodic, then

$$
\lim _{k \rightarrow \infty} \mathrm{P}\left\{w_{k} \leqslant x\right\}=\frac{1}{\mathrm{E} r_{1}}\left(1+\sum_{k=1}^{\infty} \mathrm{P}\left\{\min _{1 \leqslant j \leqslant k} S_{1, j}>0, \mathbb{S}_{1, k} \leqslant x\right\}\right),
$$

where $S_{1, k}=S_{1, k-1}+X_{1, k}, k \geqslant 1$.

We show in the next section that in some class of queueing systems, including those described by (4), the limiting distribution of waiting time is the same as the distribution of the supremum of a process $\xi$ described above.

2. Factorization. Let $h$ be the mapping of $D=D[0, \infty)$ in $R$ defined by

$$
h(x)=\sup _{0 \leqslant t<\infty} x(t), \quad x \in D
$$


LEMMA 1. If $x_{n} \in D, n \geqslant 1, x_{n}(0)=x(0)=0$, and

$$
\lim _{t \rightarrow \infty} x(t)=-\infty, \quad x_{n} \stackrel{d}{\rightarrow} x \in D,
$$

then $h\left(x_{n}\right) \rightarrow h(x)$.

Proof. Since

$$
x_{n} \stackrel{d}{\rightarrow} x,
$$

there exists a sequence $\left\{\lambda_{n}\right\}, \lambda_{n} \in \Lambda$ (see [3]), such that, for any $a>0$,

and

$$
\sup _{0<t \leqslant a}\left|x_{n}\left(\lambda_{n}(t)\right)-x(t)\right| \rightarrow 0 \quad \text { as } n \rightarrow \infty
$$

$$
\sup _{0 \leqslant t<\infty}\left|\lambda_{n}(t)-t\right| \rightarrow 0 \quad \text { as } n \rightarrow \infty
$$

Since

$$
\lim _{t \rightarrow \infty} x(t)=-\infty
$$

there exists a positive number $b_{1}$ such that $x(t)<0$ for $t>b_{1}$. Hence, and from the fact that $x_{n} \stackrel{d}{\rightarrow} x$, it follows that there exists a positive number $b$ such that $x_{n}(t)<0$ and $x(t)<0$ for $t>b$.

Let us note that

$$
\begin{aligned}
\left|h\left(x_{n}\right)-h(x)\right| & =\left|h\left(x_{n} \circ \lambda_{n}\right)-h(x)\right| \\
& \left.\leqslant \sup _{0 \leqslant t<\infty}\left|x_{n}\left(\lambda_{n}(t)\right)-x(t)\right|=\left|\sup _{0 \leqslant t \leqslant b}\right| x_{n}\left(\lambda_{n}(t)\right)-x(t)\right) \mid \\
& \leqslant \sup _{0 \leqslant t \leqslant b}\left|x_{n}\left(\lambda_{n}(t)\right)-x(t)\right| \rightarrow 0 \quad \text { ass } n \rightarrow \infty .
\end{aligned}
$$

Corollary 1. The mapping $h$ is continuous on the set

$$
A=\left\{x \in D: x(0)=0, \lim _{t \rightarrow \infty} x(t)=-\infty\right\} .
$$

LEMMA 2. Let

$$
\sum_{j=1}^{n} X_{j} \rightarrow-\infty \text { a.e. }
$$

If $w_{k} \stackrel{D}{\rightarrow} w$ and if there exist a subsequence $\left\{k_{n}, n \geqslant 1\right\}$ and a process $\xi$

then $w \stackrel{D}{=} h(\xi) . \quad \mathbb{S}_{k_{n}} \stackrel{D}{\rightarrow} \xi \quad$ in $(D, d)$,

Pro of. Let $P_{k}$ be the distribution of $S_{k}\left(P_{k}\right.$ is the probability measure
on $(D, \mathscr{D})$, where $\mathscr{D}$ is the $\sigma$-field of Borel sets in $(D, d))$. Since $P_{k_{n}} \Rightarrow P$ 
( $P$ is the distribution of $\xi$ on $(D, \mathscr{D})$ ) and

$$
\sum_{j=1}^{n} X_{j} \rightarrow-\infty \text { a.e., }
$$

we have $P\{A\}=1$, where $A$ is as in Corollary 1 . The equality $w_{k}=h\left(\mathbb{S}_{k}\right)$, $k \geqslant 1$ (see [5]), and the convergence $w_{k} \stackrel{D}{\rightarrow} w$ imply that $P_{k} h^{-1} \Rightarrow \mu(\mu$ is the distribution of $w)$. From the continuity of the mapping $h$ on the set $A$ and from the fact $P\{A\}=1$ we obtain the convergence $P_{k_{n}} h^{-1} \Rightarrow P h^{-1}$ (see Theorem 5.1 in [1]). $P h^{-1}$ is the probability measure on $(R, \mathscr{R})$. Consequently, we obtain $P_{k} h^{-1} \Rightarrow P h^{-1}$ and $P h^{-1}=\mu$.

TheOREM 1. Let

$$
\sum_{j=1}^{n} X_{j} \rightarrow-\infty \text { a.e. }
$$

If $\left\{S_{k}\right\}$ is tight in $(D, d)$ and $w_{k} \stackrel{D}{\rightarrow} w$, then $w \stackrel{D}{=} h(\xi)$ and the process $\xi(t)$ is given by (1). The process $\xi$ is any limit of a subsequence of the sequence $\left\{S_{k}\right\}$.

Proof. If the conditions of Theorem 1 are fulfilled, then so are those of Lemma 2. Hence $w \stackrel{D}{=} h(\xi)$. The trajectories of $S_{k}$ are step functions and the set of points of discontinuity of $\mathbb{S}_{k}$ is equal to the set of all nonnegative integer numbers which do not exceed $k$. Therefore, $\xi$ is discontinuous on the set of all non-negative integer numbers. Hence the process $\xi(t)$ is given by (1). Now we show that $\left\{\xi_{k}\right\}$ is a stationary sequence of r. $\nabla$.'s. Since the sequence $\left\{\boldsymbol{S}_{k}\right\}$ is tight in the metric space $(D, d)$, Prokhorov's theorem (see [1]) implies that the sequence of probability measures $\boldsymbol{P}_{k}, k \geqslant 1$, which are the distributions of $\boldsymbol{S}_{k}$, respectively, is relatively compact. Therefore, there exists a subsequence $\left\{k_{l}, l \geqslant 1\right\}$ such that

$$
\begin{aligned}
\left(\mathbb{S}_{k_{l}}\left(\bar{s}_{1}\right)-S_{k_{l}}\left(\bar{t}_{1}\right),\right. & \left.S_{k_{l}}\left(\bar{s}_{2}\right)-S_{k_{l}}\left(\bar{t}_{2}\right), \ldots, S_{k_{l}}\left(\bar{s}_{m}\right)-S_{k_{l}}\left(\bar{t}_{m}\right)\right) \\
& \stackrel{D}{\rightarrow}\left(\xi\left(\bar{s}_{1}\right)-\xi\left(\bar{t}_{1}\right), \xi\left(\bar{s}_{2}\right)-\xi\left(\bar{t}_{2}\right), \ldots, \xi\left(\bar{s}_{m}\right)-\xi\left(\bar{t}_{m}\right)\right),
\end{aligned}
$$

where $\bar{t}_{k}=t_{k}-\varepsilon, \bar{s}_{k}=s_{k}+\varepsilon, 0<\varepsilon<1$, and $t_{k}, s_{k}$ for $1 \leqslant k \leqslant m$ are nonnegative integers with

$$
0 \leqslant t_{1}<s_{1} \leqslant t_{2}<s_{2} \leqslant \ldots \leqslant t_{m}<s_{m} .
$$

Let us note that the random vector on the left-hand side of (5) has the same distribution function as the following random vector:

$$
\left(\sum_{j=k_{l}-s_{1}}^{k_{l}-t_{1}} X_{j}, \sum_{j=k_{l}-s_{2}}^{k_{l}-t_{2}} X_{j}, \ldots, \sum_{j=k_{l}-s_{m}}^{k_{l}-t_{m}} X_{j}\right) .
$$

Let $n_{l}=k_{l}-t_{1}$. Then the random vector in (6) has the same distribution function as

$$
\left(S_{n_{l}}\left(\bar{s}_{1}-t_{1}\right), \mathbb{S}_{n_{l}}\left(\bar{s}_{2}-t_{1}\right)-S_{n_{l}}\left(t_{2}-\bar{t}_{1}\right), \ldots, S_{n_{l}}\left(\bar{s}_{m}-t_{1}\right)-S_{n_{l}}\left(t_{m}-\bar{t}_{1}\right)\right)
$$


Since $\left\{\boldsymbol{P}_{k}\right\}$ is relatively compact, there exists a subsequence $\left\{n_{l_{r}}, r \geqslant 1\right\}$ of $\left\{n_{l}, l \geqslant 1\right\}$ such that

$$
\mathbb{S}_{n_{l_{r}}} \stackrel{D}{\rightarrow} \xi \text { in }(D, d) \quad \text { as } r \rightarrow \infty .
$$

Therefore, (7) converges in distribution to

$$
\left(\xi\left(\bar{s}_{1}-t_{1}\right), \xi\left(\bar{s}_{2}-t_{1}\right)-\xi\left(t_{2}-\bar{t}_{1}\right), \ldots, \xi\left(\bar{s}_{m}-t_{1}\right)-\xi\left(t_{m}-\bar{t}_{1}\right)\right)
$$

which has the same distribution function as

$$
\left(\xi\left(s_{1}-t_{1}\right), \xi\left(s_{2}-t_{1}\right)-\xi\left(t_{2}-t_{1}\right), \ldots, \xi\left(s_{m}-t_{1}\right)-\xi\left(t_{m}-t_{1}\right)\right) .
$$

Hence we obtain the assertion of the theorem.

CoRollary 2. If the conditions of Theorem 1 are fulfilled and if $X_{k}$, $k \geqslant 1$, are independent, then $\xi_{k}, k \geqslant 1$, are independent and identically distributed.

3. Tightness criterion of $\left\{S_{k}\right\}$.

THEOREM 2 (see [1] and [3]). The sequence $\left\{P_{k}\right\}$ of probability measures is tight in $(D, \mathscr{D})$ if and only if

(i) for any $c, \eta>0$ there exists $a>0$ such that, for every $n \geqslant 1$,

$$
P_{n}\left\{x: \sup _{0 \leqslant t \leqslant c}|x(t)|>a\right\} \leqslant \eta ;
$$

(ii) for any positive real numbers $\varepsilon$ and $\eta$ there exists a real number $\delta$ such that, for every $n \geqslant 1$,

$$
P_{n}\left\{x: w_{x}^{\prime \prime}(\delta) \geqslant \varepsilon\right\} \leqslant \eta \quad \text { and } \quad P_{n}\left\{x: w_{x}[0, \delta] \geqslant \varepsilon\right\} \leqslant \eta ;
$$

(iii) for any positive real numbers $b, \varepsilon$, and $\eta$ there exists a real number $\delta$ such that, for every $n \geqslant 1$,

where

$$
P_{n}\left\{x: w_{x}[b-\delta, b] \geqslant \varepsilon\right\} \leqslant \eta,
$$

$$
\begin{gathered}
w_{x}^{\prime \prime}(\delta)=\sup _{t_{1} \leqslant t \leqslant t_{2}, t_{2}-t_{1} \leqslant 0} \min \left\{\left|x(t)-x\left(t_{1}\right)\right|,\left|x\left(t_{2}\right)-x(t)\right|\right\}, \\
w_{x}[u, v]=\sup _{u \leqslant s \leqslant t \leqslant v}|x(t)-x(s)| .
\end{gathered}
$$

THEOREM 3. $\left\{S_{k}\right\}$ is tight in $(D, d)$ if and only if for any positive number $\eta$ and integer $m$ there exists a positive number a such that, for every $k \geqslant 1$,

$$
\mathrm{P}\left\{\sup _{k-m \leqslant j \leqslant k}\left|\sum_{l=j}^{k} X_{l}\right| \geqslant a\right\} \leqslant \eta .
$$

Proof. It is obvious that condition (i) is fulfilled if the conditions of
Theorem 3 are satisfied. Therefore, we show only that (ii) and (iii) are 
fulfilled. But this follows from the definitions of $w_{x}^{\prime \prime}(\delta), w_{x}[u, v]$ and $s_{k}$. Indeed, let us note that for $\delta<1 / 2$ we have

$$
\begin{aligned}
\sup _{t_{1} \leqslant t \leqslant t_{2}, t_{2}-t_{1} \leqslant 1 / 2} \min \left\{\left|S_{k}(t)-S_{k}\left(t_{1}\right)\right|,\left|S_{k}\left(t_{2}\right)-S_{k}(t)\right|\right\} \\
=\sup _{t_{1} \leqslant t \leqslant t_{2}, t_{2}-t_{1} \leqslant 1 / 2} \min \left\{\left|\sum_{j=[k-t+]+1}^{\left[k-t_{1}+\right]} X_{j}\right|,\left|\sum_{j=\left[k-t_{2}+\right]+1}^{[k-t+]} X_{j}\right|\right\}=0 .
\end{aligned}
$$

In a similar way one can show that

$$
\sup _{0 \leqslant 8 \leqslant t \leqslant 1 / 2}\left|S_{k}(t)-S_{k}(s)\right|=0 \quad \text { and } \quad \sup _{b-1 / 2 \leqslant s<t<b}\left|S_{k}(t)-S_{k}(s)\right|=0
$$

COROLLARY 3. If $\left\{X_{k}\right\}$ is such that for every $m \geqslant 1$ the sequence $\left\{\left|X_{k+1}\right|+\left|X_{k+2}\right|+\ldots+\left|X_{k+m}\right|, k \geqslant 1\right\}$ of $r$. v.'s is tight, then $\left\{\boldsymbol{S}_{k}\right\}$ is tight in $(D, d)$.

Proof. This fact follows from

$$
\sup _{k-m \leqslant j \leqslant k}\left|X_{k}+X_{k-1}+\ldots+X_{j}\right| \leqslant \sum_{j=k-m}^{k}\left|X_{j}\right| .
$$

Let us write

$$
\begin{gathered}
X(n)=\left\{X_{k+n-1}, k \geqslant 1\right\}, \quad n \geqslant 1, \\
\vartheta_{n}=\max \left\{k<n: w_{k}=0\right\}, \quad n \geqslant 1,
\end{gathered}
$$

where $w_{k}$ is defined in (2) by $\left\{X_{k}\right\}$, and let

$$
\gamma_{n}=n-\vartheta_{n}, \quad n \geqslant 1 \text {. }
$$

THEOREM 4. Let $\left\{X_{k}\right\}$ be such that for $k \leqslant n$

$$
\mathbf{P}\left\{X(n) \in B \mid \gamma_{n}=k\right\}=\mathrm{P}\{X(k) \in B\},
$$

where $B$ is a Borel set in $R^{\infty}$. If $w_{k} \stackrel{D}{\rightarrow}$ w and $\mathrm{P}\{w<\infty=1\}$, then $\left\{S_{k}\right\}$ is tight in $(D, d)$.

Proof. It follows from Theorem 3 that it is enough to show the $\nabla a^{-}$ lidity of (i). Suppose that (i) does not hold. Then there exist numbers $m$ and $\eta$ such that for every positive integer $n$ there exists a positive integer $k_{n}$ such that

$$
\mathbf{P}\left\{\sup _{k_{n}-m \leqslant j \leqslant k_{n}}\left|\sum_{l=j}^{k_{n}} X_{l}\right|>n\right\} \geqslant \eta .
$$

Since $w_{k} \stackrel{D}{\rightarrow} w$ and $\mathrm{P}\{w<\infty\}=1$, inequality (8) can be replaced bJ

$$
\mathbf{P}\left\{\inf _{k_{n}-m \leqslant j \leqslant k_{n}}\left(S_{k_{n}}-S_{j}\right)<-n\right\} \geqslant \eta
$$


By the formula for the total probability and by the conditions of the theorem, the left-hand side of (9) can be written as

$$
\begin{aligned}
\sum_{s=1}^{k_{n}-m} \mathrm{P}\left\{\inf _{k_{n}-m \leqslant j \leqslant k_{n}}\left(S_{k_{n}}-S_{j}\right)<-n \mid \gamma_{k_{n}-m}=s\right\} \mathrm{P}\left\{\gamma_{k_{n}-m}=s\right\} \\
=\sum_{s=1}^{k_{n}-m} \mathrm{P}\left\{\inf _{s<j \leqslant s+m}\left(\mathbb{S}_{m+s}-S_{j}\right)<-n\right\} \mathrm{P}\left\{\gamma_{k_{n}-m}=s\right\} .
\end{aligned}
$$

Let us note that for each $s \geqslant 1$

$$
\mathbf{P}\left\{\inf _{s \leqslant j \leqslant m+s}\left(\mathbb{S}_{m+8}-\mathbb{S}_{j}\right)<-n\right\} \rightarrow 0 \text { as } n \rightarrow \infty .
$$

Hence (10) tends to zero as $n \rightarrow \infty$ which contradicts inequality (8). Thus (8) does not hold.

4. Heavy traffic. Let us consider the family of processes $\left\{w_{k}^{a}, k \geqslant 1\right\}$ with parameter $a<0$, such that $\left\{w_{k}^{a}, k \geqslant 1\right\}$ is defined for every $a$ by some sequence $\left\{X_{k}\right\}$ in (2). If

$$
\begin{gathered}
w_{k}^{a} \stackrel{D}{\rightarrow} w^{a}, \quad \mathrm{P}\left\{w^{a}<\infty\right\}=1, \quad w^{a} \stackrel{D}{=} h\left(\xi^{a}\right), \\
\xi^{a}(t)=\sum_{j=1}^{[t]} \xi_{j}^{a}, \quad t \geqslant 0,
\end{gathered}
$$

then we accept the interpretation $a=\mathrm{E} \xi_{1}^{a}$.

Let us define the sequence of processes $\vec{\xi}_{n}^{a}$ by

$$
\bar{\xi}_{n}^{a}(t)=\frac{1}{\sqrt{n}} \sum_{j=1}^{[n t]}\left(\xi_{j}^{a}-a\right), \quad t \geqslant 0 .
$$

Theorem 5. Let the conditions of Theorem 1 be satisfied. If for every $a$ there exists a $\sigma_{a}$ such that $\sigma_{a} \rightarrow \sigma>0$ as $a \rightarrow 0$, and

$$
\frac{1}{\sigma_{a}} \bar{\xi}_{n}^{a} \stackrel{D}{\rightarrow} \mathscr{W} \text { in }(D, d) \quad \text { as } n \rightarrow \infty
$$

where $\mathscr{W}$ is a Wiener process in $D$, then the distribution of $\left(1 / \sigma_{a}\right)|a| w^{a}$ converges Proof. By Theorem 1 we have

Where

$$
\begin{gathered}
\xi^{a}(t)=\bar{\xi}^{a}(t)+a[t], \quad t \geqslant 0, \\
\bar{\xi}^{a}(t)=\sum_{j=1}^{[t]}\left(\xi_{j}^{a}-a\right), \quad t \geqslant 0 .
\end{gathered}
$$


Let us define the families of processes $\xi_{c}^{a}$ and $\vec{\xi}_{c}^{a}, c>0$, by

$$
\begin{aligned}
& \xi_{c}^{a}(t)=\frac{1}{\sqrt{c}} \xi^{a}(t c), \quad t \geqslant 0, \\
& \xi_{c}^{a}(t)=\frac{1}{\sqrt{c}} \xi^{a}(t c), \quad t \geqslant 0,
\end{aligned}
$$

and the family of mappings $x_{c}: D \rightarrow D$ by

$$
x_{c}(x)(t)=x\left(\frac{c}{[c]} t\right), \quad t \geqslant 0, x \in D .
$$

The mappings $x_{c}$ are $\mathscr{D}$-measurable and $x_{c_{n}}\left(x_{n}\right) \stackrel{d}{\rightarrow} x$ as $x_{n} \rightarrow x$, $x \in C[0, \infty)(x$ is continuous on $[0, \infty))$ and $c_{n} \rightarrow \infty$ (see [5]).

Let

$$
E=\left\{x \in D: \varkappa_{c_{n}}\left(x_{n}\right)+x \text { for some } x_{n} \stackrel{d}{\rightarrow} x\right\} .
$$

Note that

$$
\varkappa_{c}\left(\bar{\xi}_{[c]}^{a}\right)=\bar{\xi}_{c}^{a} \sqrt{\frac{c}{[c]}} .
$$

But $E \cap C[0, \infty)=\varnothing$ (see [5]), thus by (11), (12) and Theorem 5.5 in [1] we obtain

$$
\frac{1}{\sigma_{a}} \xi_{1 / a^{2}}^{a} \stackrel{D}{\rightarrow} \mathscr{W}-I \frac{1}{\sigma} \text { in }(D, d) \quad \text { as } a \rightarrow 0 .
$$

Hence, using Theorem 5.1 in [1] and Lemma 3.4 in [5], we have

$$
\frac{1}{\sigma_{a}}|a| w^{a} \stackrel{D}{\rightarrow} \sup _{0 \leqslant t<\infty}\left(\mathscr{W}(t)-\frac{t}{\sigma}\right) \quad \text { as } a \rightarrow 0 \text {. }
$$
bution.

But the r. $\nabla . \sup _{0 \leqslant t<\infty}(\mathscr{W}(t)-t / \sigma)$ has the negative exponential distri-

COROLLARY 4. Let for each parameter a the sequence $\left\{X_{k}^{a}, k \geqslant 1\right\}$ describe a sequence $\left\{w_{k}^{a}, k \geqslant 1\right\}$ such that the conditions of Theorem 1 are fulfilled. Furthermore, let for each a the $r . v$.'s $X_{k}^{a}, k \geqslant 1$, be independent and let

$$
\sigma_{a}^{2}=\operatorname{Var}\left(\xi_{1}^{a}\right) \rightarrow \sigma>0 \quad \text { as } a \rightarrow 0 .
$$

Then the limiting distribution of $\left(1 / \sigma_{a}\right)|a| w^{a}$ as $a \rightarrow 0$ is a negative exponential distribution.

Similar results can be obtained for the virtual waiting time. This fact follows from the equality (see (3.1.5) in [5])

$$
\begin{gathered}
W(t)=h\left(\mathscr{L}_{t}\right), \quad t \geqslant 0, \\
\mathscr{L}_{t}(s)=L(t)-L(t-s+), \quad s \geqslant 0, L(t)=\sum_{j=1}^{N(t)} v_{j}-t, t \geqslant 0,
\end{gathered}
$$


where the symbol $L\left(t-s_{0}+\right)$ denotes the right-hand limit of $L(t-s)$ at the point $s_{0}<t$ for any fixed elementary random event and zero for $8_{0} \geqslant t$.

\section{References}

[1] P. B. Bilingsley, Oonvergenoe of probability measures, J. Wiley, New York 1968.

[2] A. A. B orovkov (A. A. Боро вков), Вероятностные прочессы в теории массового обслужсивания, Наука, Москва 1972.

[3] T. Lindwall, Weak convergence of probability measures and random function in the function space $D[0, \infty)$, J. Appl. Prob. 10 (1973), p. 109-121.

[4] R. M. Loy $\mathrm{nes}$, The stability of queues with nonindependent interarrival and service time, Proc. Camb. Phil. Soc. 58 (1962), p. 467-520.

[5] W. Szczotka, An invariance principle for queues in heavy traffic, Institute of Mathematics, Polish Academy of Sciences 1976, preprint no. 91.

MATHEMATICAL INSTITUTE

UNIVERSITY OF WROCEAW

50-384 WROCEAW

Received on 10. 1. 1977

W. Szczotra (Wroelaw)

FAKTORYZACJA ROZKRADU CZASU CZEKANIA

STRESZCZENIE

Głównym rezultatem pracy jest pokazanie, że w dostatecznie szerokiej klasio systemów kolejkowych graniczny rozkład czasu czekania jest taki sam jak rozkład supremum procesu

$$
\xi(t)=\sum_{j=1}^{[t]} \xi_{j}, \quad t>0,
$$

gdzie $\left\{\xi_{k}, k>1\right\}$ jest stacjonarnym cįgiem zmiennych losowych, a [•] oznacza funkcje entier. Przyjmujemy również, że suma po pustym zbiorze wskaźników jest równa zeru.

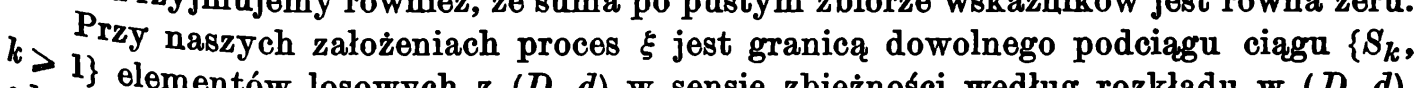
gdzie elementów losowych z $(D, d)$ w sensie zbieżności według rozkładu w $(D, d)$,

$$
\mathrm{S}_{k}(t)=\sum_{j=[k-t+]+1}^{k} X_{j}, \quad t>0,
$$

a $\left\{X_{k}, k \geq 1\right\}$ jest ciagiem zmiennych losowych, generujacym system kolejkowy. $t_{0}>t$. $\left[k-t_{0}+\right]$ oznacza prawostronną granice $[k-t] \mathrm{w}$ punkcio $t_{0}<k$ i zero dla 